\title{
Ethylene Controls Adventitious Root Initiation Sites in Arabidopsis Hypocotyls Independently of Strigolactones
}

\author{
Amanda Rasmussen ${ }^{1,2}$ - Yuming $\mathrm{Hu}^{3} \cdot$ Thomas Depaepe $^{3}$ - Filip Vandenbussche ${ }^{3}$. \\ Francois-Didier Boyer ${ }^{4} \cdot$ Dominique Van Der Straeten $^{3} \cdot$ Danny Geelen $^{2}$
}

Received: 28 September 2016 / Accepted: 8 February 2017 / Published online: 28 March 2017

(c) The Author(s) 2017. This article is an open access publication

\begin{abstract}
Adventitious root formation is essential for cutting propagation of diverse species; however, until recently little was known about its regulation. Strigolactones and ethylene have both been shown to inhibit adventitious roots and it has been suggested that ethylene interacts with strigolactones in root hair elongation. We have investigated the interaction between strigolactones and ethylene in regulating adventitious root formation in intact seedlings of Arabidopsis thaliana. We used strigolactone mutants together with 1-aminocyclopropane-1-carboxylic acid (ACC) (ethylene precursor) treatments and ethylene
\end{abstract}

Yuming Hu and Thomas Depaepe have contributed equally to this work.

The original version of this article was revised: The name of the sixth author was misspelled. However, it has been corrected in this version.

Electronic supplementary material The online version of this article (doi:10.1007/s00344-017-9692-8) contains supplementary material, which is available to authorized users.

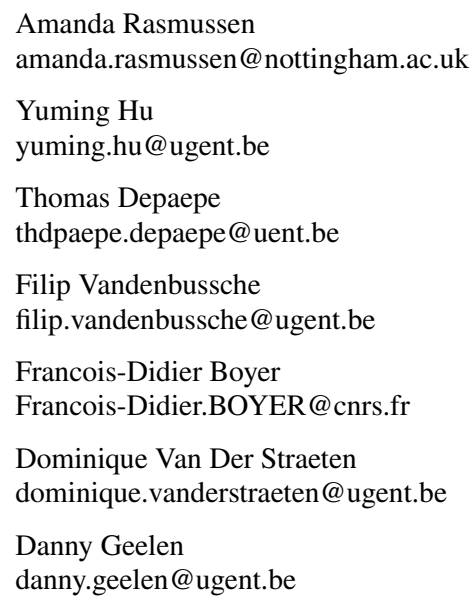

mutants together with GR24 (strigolactone agonist) treatments. Importantly, we conducted a detailed mapping of adventitious root initiation along the hypocotyl and measured ethylene production in strigolactone mutants. ACC treatments resulted in a slight increase in adventitious root formation at low doses and a decrease at higher doses, in both wild-type and strigolactone mutants. Furthermore, the distribution of adventitious roots dramatically changed to the top third of the hypocotyl in a dose-dependent manner with ACC treatments in both wild-type and strigolactone mutants. The ethylene mutants all responded to treatments with GR24. Wild type and $\max 4$ (strigolactone-deficient mutant) produced the same amount of ethylene, while emanation from $\max 2$ (strigolactone-insensitive mutant) was lower. We conclude that strigolactones and ethylene act largely independently in regulating adventitious root formation with ethylene controlling the distribution of root initiation sites. This role for ethylene may have implications for

1 Plant and Crop Sciences, School of Biosciences, The University of Nottingham, Sutton Bonington, Leicestershire LE12 5RD, UK

2 Plant Production, Faculty of Bioscience Engineering, Ghent University, Coupure links 653, 9000 Ghent, Belgium

3 Laboratory of Functional Plant Biology, Faculty of Sciences, Ghent University, K.L. Ledeganckstraat 35, 9000 Ghent, Belgium

4 Centre de Recherche de Gif, Institut de Chimie des Substances Naturelles, UPR2301 CNRS, INRA, 1 avenue de la Terrasse, 91198 Gif-sur-Yvette Cedex, France 
flood response because both ethylene and adventitious root development are crucial for flood tolerance.

Keywords Adventitious roots - Arabidopsis - Ethylene · Etiolation $\cdot$ Hypocotyl zonation $\cdot$ Strigolactone

\section{Introduction}

Adventitious root formation is the formation of roots from non-root tissues such as stem or leaf tissues and is critical for propagation of forestry and horticultural species and for tissue culture systems. Several hormones such as auxins, cytokinins, and ethylene have long been known to regulate adventitious root formation (De Klerk and others 1999). However, recalcitrance of plants to adventitious rooting persists as a problem in many horticultural and forestry species. Although differences exist between adventitious root formation on cuttings in the light (Rasmussen and others 2012a) compared to intact pea seedlings in the dark (Urquhart and others 2015), a new class of plant hormones, strigolactones, was shown to regulate adventitious root formation in both Arabidopsis (Arabidopsis thaliana) intact seedlings, and in pea (Pisum sativum) (Rasmussen and others 2012a) and tomato (Solanum lycopersicum) stem cuttings (Kohlen and others 2012). It was shown that strigolactone may act together with auxin to regulate adventitious root formation (Rasmussen and others 2012a). Furthermore, inhibition of strigolactones was able to stimulate adventitious root formation across a range of species (Rasmussen and others 2012b) demonstrating the potential industrial applications of manipulating strigolactone signaling. However, to maximize this potential, understanding how strigolactones interact with other known regulators of adventitious roots is essential.

Strigolactones were originally discovered for their promotion of mycorrhizal association (Akiyama and others 2005) and parasitic weed seed germination (Cook and others 1966; Matusova and others 2005), and more recently found to inhibit shoot axillary bud outgrowth (GomezRolden and others 2008; Umehara and others 2008). Orthologous strigolactone signaling and synthesis genes have been found in all higher plant species examined, most notably Arabidopsis, pea, tomato, petunia (Petunia hybrida), rice (Oryza sativa), and chrysanthemum (Dendranthema grandiflorum) in which loss-of-function mutations in these genes result in increased bud outgrowth (Drummond and others 2009; Beveridge and Kyozuka 2010; Liang and others 2010; de Saint Germain and others 2013). Strigolactones are produced from CAROTENOID CLEAVAGE DIOXYGENASE 7 and 8 (CCD7/ MAX3 and CCD8/MAX4), downstream of which, MORE AXILLARY BRANCHES 1 (MAX1), a cytochrome P450 enzyme, likely acts on a mobile intermediate in the production of strigolactones (Booker and others 2005). The response to strigolactones requires an F-Box leucine-rich repeat protein encoded by MAX2/RAMOSUS4/DWARF3 (MAX2/RMS4/D3; Stirnberg and others 2007; GomezRolden and others 2008; Umehara and others 2008; de Saint Germain and others 2013) and an $\alpha / \beta$ hydrolase encoded by D14 (Arite and others 2009; Hamiaux and others 2012; Kagiyama and others 2013; Yao and others 2016). Strigolactones have also been demonstrated to regulate other aspects of the root system, including root growth, root hair development, and lateral root formation (Koltai and others 2010; Kapulnik and others 2011a, b; Rasmussen and others 2013).

It has been suggested that ethylene may act downstream of strigolactone in stimulation of root hair elongation (Kapulnik and others 2011b). Furthermore, it has been shown that strigolactone increased production of ethylene in Striga hermonthica seeds while blocking ethylene production, together with strigolactone treatment resulted in no germination of the Striga seeds (Logan and Stewart 1991; Sugimoto and others 2003). These findings support the hypothesis that strigolactone induces ethylene production which in turn affects root hair lengths and germination of parasitic weed seeds. In this study, we investigated whether ethylene interacts with strigolactone in the regulation of adventitious root formation.

In Arabidopsis, ethylene is synthesized from methionine through 1-aminocyclopropane-1-carboxylic acid (ACC) by the subsequent action of a family of ACC synthases and ACC oxidases (De Paepe and Van Der Straeten 2005). Dominant mutations in ACC synthases, like ethylene overproducer 2/ACC synthase 5 (eto2/acs5) and eto3/acs 9 lead to ethylene overproduction (Chae and others 2003). In essence, perception and signal transduction of ethylene in Arabidopsis rely on five ethylene receptors and the central inhibitor of the pathway, CONSTITUTIVE TRIPLE RESPONSE 1 (CTR1) (reviewed in Van de Poel and others 2015). In the presence of ethylene, the receptors relieve their activation of CTR1, leading to derepression. As a consequence, the C-terminal portion of the downstream ER-membrane-localized component ETHYLENEINSENSITIVE 2 (EIN2) accumulates in the nucleus, where it positively regulates subsequent nuclear steps, including accumulation of the transcription factor EIN3 and triggering ethylene responses (Qiao and others 2012). Hence, whereas loss-of-function ctrl mutants have constitutive ethylene responses, disruption of EIN2 and EIN3 causes ethylene insensitivity.

Studies on the effect of ethylene on adventitious rooting under non-waterlogged conditions have produced contrasting results. For example in tobacco (Nicotiana tabacum L.; McDonald and Visser 2003) and Prunus avium (Biondi 
and others 1990), ethylene treatments reduced adventitious rooting. This response was significantly reduced in the tobacco ethylene-insensitive mutant Tetr compared to the wild type (McDonald and Visser 2003). In contrast, the ethylene precursor ACC enhanced adventitious rooting in non-waterlogged, etiolated hypocotyls of tomato (Negi and others 2010) and in stem cuttings of mung bean (Vigna radiata; Riov and Yang 1989) and sunflower (Helianthus annuus; Liu and others 1990). Supporting this result, the Never ripe $(\mathrm{Nr})$ ethylene-insensitive mutant in tomato produced fewer adventitious roots, whereas the ethylene-overproducing mutant epinastic (epi) produced more (Negi and others 2010). In apple (Malus domestica Borkh), ethylene appeared to have no effect on adventitious rooting (Harbage and Stimart 1996). Adding even more complexity, at high auxin levels ethylene is inhibitory in mung bean and eucalyptus hybrids (De Klerk and Hanecakova 2008; Kilkenny and others 2012), whereas at low auxin levels ethylene promoted adventitious rooting in mung bean (De Klerk and Hanecakova 2008).

Many studies have shown that ethylene regulates root elongation (Ruzicka and others 2007; Stepanova and others 2007; Swarup and others 2007), and findings that lateral root development is inhibited by ethylene in Arabidopsis (Ivanchenko and others 2008; Lewis and others 2011), tomato (Negi and others 2010), and radish (Raphanus sativus L.; Radin and Loomis 1969) also provide further support for the role of ethylene in root development. Moreover, addition of ethylene to DR5rev:GFP seedlings demonstrated a reduced GFP signal in the root tip and elongation zone of mature roots (Ruzicka and others 2007; Lewis and others 2011) supporting the idea that ethylene regulates lateral root development via a reduction in local auxin signal. Also in adventitious root development in Arabidopsis hypocotyls, auxin plays a central role. The auxin maximum required for adventitious root production appears as the result of a concerted action of the YUCCA6 auxin biosynthesis enzyme and auxin transport dependent on AUXIN1, LIKE AUXIN 1-3, and PIN FORMED1 (Della Rovere and others 2013).

Here, we used strigolactone and ethylene mutants together with pharmacological treatments to test whether strigolactones change ethylene signaling or response or vice versa to regulate adventitious root formation.

\section{Materials and Methods}

\section{Plant Materials and Growth Conditions}

Arabidopsis seeds were gas sterilized for $4 \mathrm{~h}$ (chlorine gas created using (5\% hypochlorite): $\mathrm{HCl}(100: 3 \mathrm{v}: \mathrm{v})$ in a $10 \mathrm{~L}$ container within the fume hood) and sown on square agar plates containing $10 \mathrm{~g} \mathrm{~L}^{-1}$ phytagel (Sigma-Aldrich, http://www.sigmaaldrich.com); $5 \mathrm{~g} \mathrm{~L}^{-1}$ sucrose; $1.5 \mathrm{~g} \mathrm{~L}^{-1}$ Murashige and Skoog (MS) salts (Phytotechnology Laboratories, http://www.phytotechlab.com); $0.5 \mathrm{~g} \mathrm{~L}^{-1} \mathrm{MES}$ and then stratified in the dark at $4{ }^{\circ} \mathrm{C}$ for 3 days. Arabidopsis seedlings were grown in $16 \mathrm{~h}: 8 \mathrm{~h}$ day:night conditions at $22^{\circ} \mathrm{C}$. Lines used were Columbia (Col-0) wild type, $\max 2-1, \max 4-1$, ein2-1, ein2-5, ein $3-1$, etr1-1, ctr1-1, eto2-1, and eto3-1.

Induction and measurement of adventitious roots in intact Arabidopsis plants was performed using 4-day etiolation followed by 7-day growth in light as previously described (Sorin and others 2005; Rasmussen and others 2012a), with minor modifications. Briefly, for ACC experiments, wild-type Col-0 and mutant homozygous seed lines: $\max 2$ (At2g42620) and $\max 4$ (At4g32810) were placed in the dark in a controlled environment cabinet at $22^{\circ} \mathrm{C}$ for 4 days. Etiolated seedlings were then transferred to fresh agar plates containing $0,0.1,1,10$, and $100 \mu \mathrm{M}$ of ACC. The petri dishes were subsequently exposed to light $(16 \mathrm{~h} /$ day $)$ at $22{ }^{\circ} \mathrm{C}$ for 7 days. The number and distribution of adventitious roots on each seedling were recorded. Adventitious roots were only counted above the root-hypocotyl junction (and not including any roots that formed at the junction) and adventitious roots were recorded separately for the top third and the lower two-thirds. The distribution of adventitious roots is also presented in the Electronic Supplementary Materials (Supplemental Fig. S2) as a percentage of the total roots per seedling. Seedlings with zero adventitious roots are also included in all treatments to demonstrate the inhibition occurring with high ACC treatments.

Strigolactones do not affect hypocotyl length and are required in the media prior to the transfer to the light for effect (Supplemental Fig. S1; data not shown), so GR24 (racemic mixture) treatments were applied in the original media on which the ethylene mutant seeds were germinated. When testing ethylene mutants for strigolactone response, 0 or $1 \mu \mathrm{M}$ GR24 was used, whereas in the GR24 dose-response experiment for ein2, concentrations used were $0,1,10,100$, and $1000 \mathrm{nM}$. Measurements were made 7 days after transfer to the light. We previously demonstrated clear effects on adventitious root formation at these low concentrations (Rasmussen and others 2012a).

To check for an additive effect of ethylene and strigolactone in Columbia, $\max 2$, and $\max 4,0$ or $1 \mu \mathrm{M}$ GR24 was included in the media from germination. At the time of moving plates to the light, seedlings were then transferred to new plates containing 0 treatment, $1 \mu \mathrm{M}$ GR24, $10 \mu \mathrm{M}$ ACC, $100 \mu \mathrm{M}$ ACC, $10 \mu \mathrm{M}$ ACC $+1 \mu \mathrm{M}$ GR24, or $100 \mu \mathrm{M}$ $\mathrm{ACC}+1 \mu \mathrm{M}$ GR24. Measurements were made 7 days after transfer to the light. 


\section{Reporter Line Analysis}

GUS staining was performed as described in (Vandenbussche and others 2010). The ethylene reporter EBS::GUS (Stepanova and others 2007) staining patterns of the primary roots between GR24 treated and nontreated were compared.

\section{Ethylene Measurement}

Approximately 100 seeds per line were placed in a $10-\mathrm{mL}$ vial on medium containing $1.5 \mathrm{gL}^{-1}$ Murashige and Skoog medium (Duchefa Biochemie, http://www. duchefa-biochemie.nl/), $5 \mathrm{gL}^{-1}$ Sucrose (VWR; https:// be.vwr.com/), $8 \mathrm{gL}^{-1}$ Plant Tissue Culture Agar (LABM; http://www.labm.com/), and seedlings grown. Before the measurement, the vials were sealed with a rubber plug and a snap-cap (Chromacol; http://www.chromacol. $\mathrm{com} /$ ) to accumulate ethylene. The vials were flushed at a flow rate of $2 \mathrm{~L} \mathrm{~h}^{-1}$ and ethylene was measured at the selected time points during the transition from the dark to the light with a photo-acoustic detector (Thain and others 2004). For experiments on max mutants, ethylene was collected for $24 \mathrm{~h}$ on day 3 , 4, and 5 of dark growth. Three replicates per seed line were included. The assay was performed twice with similar results. For the GR24 experiment, ethylene was collected for $12 \mathrm{~h}$ on day 4 of darkness, $12 \mathrm{~h}$ before transfer to the light, and on time points $12,24,36,48,60$, and $72 \mathrm{~h}$, after transfer to the light (16h light/8h dark photoperiod) to mimic the conditions under which adventitious roots are forming. Four independent replicates of each treatment were included.

\section{Data Analysis}

The quantitative data were represented as mean $+\mathrm{SE}$. Statistical analysis was performed in R 3.2.3. (R Foundation for Statistical Computing, Vienna, Austria; https:// www.R-project.org/). Comparison of means among three or more groups was done through Analysis Of Variance. Normality of the residuals and homoscedasticity was verified by quantile-quantile plots and boxplots, respectively. Due to violation of these assumptions, non-parametric alternatives were chosen. The Scheirer-Ray-Hare extension of the Kruskal Wallis rank sum test was applied followed by post hoc Wilcoxon rank sum tests $(P<0.05)$ for multiple pairwise comparisons (with Bonferroni correction for multiple testing). To compare average ethylene production in Fig. 2, a Student's $t$ test (two-tailed; $P<0.05)$ was applied.

\section{Results}

\section{Strigolactone Mutant Responses to the Ethylene Precursor ACC}

Because there are conflicting results regarding the role of ethylene in adventitious root formation (Harbage and Stimart 1996; McDonald and Visser 2003; Negi and others 2010), and because the response to ACC of adventitious roots in Arabidopsis has not previously been reported, we first analyzed the ethylene response in our conditions (intact dark grown seedlings after transfer to light), for the Columbia (Col-0) wild type of Arabidopsis on the total number of adventitious roots. To determine the order of action of ethylene and strigolactone in regulating adventitious root formation, the effect of increased concentrations of ACC on strigolactone-insensitive ( $\max 2)$ and strigolactone-deficient (max4) mutants was analyzed in parallel. One and $10 \mu \mathrm{M}$ are commonly used concentrations of ACC (Ruzicka and others 2007; Swarup and others 2007; De Klerk and Hanecakova 2008; Negi and others 2010; Ellison and others 2011) so we chose a dose-response assay which included these concentrations. As a stress hormone, ethylene can accumulate to very high levels. Hence, to have a complete coverage of the physiological range we extended treatments to $100 \mu \mathrm{M}$ ACC (Vriezen and others 2003; Achard and others 2006).

Application of the ethylene precursor ACC did not induce any significant changes in adventitious root formation in wild-type seedlings (Fig. 1a). Nonetheless, a small increase, from 2.5 to 3 roots on average, was visible at low concentrations $(0.01 \mu \mathrm{M})$, whereas a higher dose $(100 \mu \mathrm{M})$ tended to inhibit adventitious root formation to $<2$ roots for wild-type seedlings. Interestingly, this trend was more pronounced in $\max 2$ and $\max 4$, indicating that the strigolactone mutants may be more sensitive to ACC than the wild type. At low concentrations $(0.01 \mu \mathrm{M}), \mathrm{ACC}$ tended to increase the number of adventitious roots in max mutants, $\max 2$ appearing more sensitive than both $\max 4$ and the wild type $(P<0.05)$. Adventitious root formation in both $\max 2$ and $\max 4$ was inhibited at the highest dose of ACC (100 $\mu \mathrm{M} ; P<0.05)$.

The contrasting low versus high concentration effect matches the response in lateral root formation (Kapulnik and others 2011a) and highlights the importance of detailed dose-responses for reporting the effect of ethylene on adventitious root formation.

However, we expected a larger response in the adventitious root formation given the higher response in other species (Lorbiecke and Sauter 1999; Negi and others 2010), so to check the activity of our ACC stocks we measured hypocotyl elongation on seedlings treated with ACC during the etiolation period (Supplemental Fig. S1). The expected 

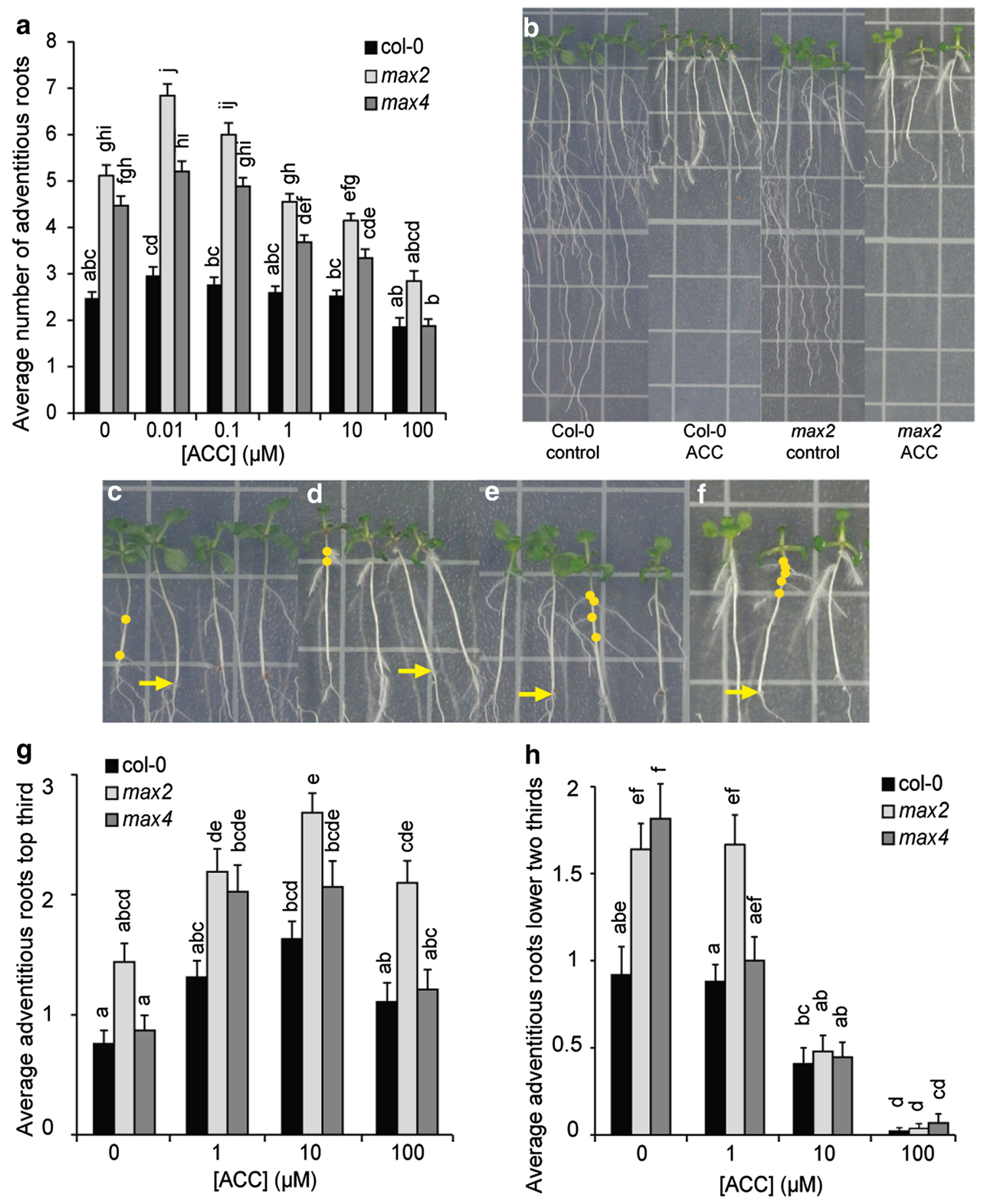

Fig. 1 In etiolated seedlings, ACC has a differential effect on adventitious rooting of the upper hypocotyl compared to the lower hypocotyl. a Average number of adventitious roots with increasing concentrations of ACC on Columbia wild type (col), $\max 2$ strigolactone-insensitive mutant, and $\max 4$ strigolactone production mutant. b Phenotype of Columbia wild type and $\max 2$ without ACC or with $10 \mu \mathrm{M}$ ACC, 1 square $=10 \mathrm{~mm}$. c-f Closer view of the etiolated hypocotyl showing the distribution of adventitious roots for Columbia control (c), Columbia $+10 \mu \mathrm{M}$ ACC (d), max2 control (e), and

$\max 2+10 \mu \mathrm{M}$ ACC (f) arrows point to the hypocotyl-root junction, dots mark out sites of adventitious root initiation. $\mathbf{g}$ and $\mathbf{h}$ The average number of adventitious roots forming in the top 3rd (g) and lower $2 / 3^{\text {rds }}(\mathbf{h})$ of the hypocotyl for Columbia wild type, $\max 2$, and $\max 4$ at increasing ACC concentrations. Means are presented \pm standard error bars. Different letters represent means that are significantly different. Statistical analysis through Scheirer-Ray-Hare test $(P<0.05)$ followed by post hoc Wilcoxon rank sum test $(P<0.05)(n>30$ per biological repeat, 4 biological repeats) 

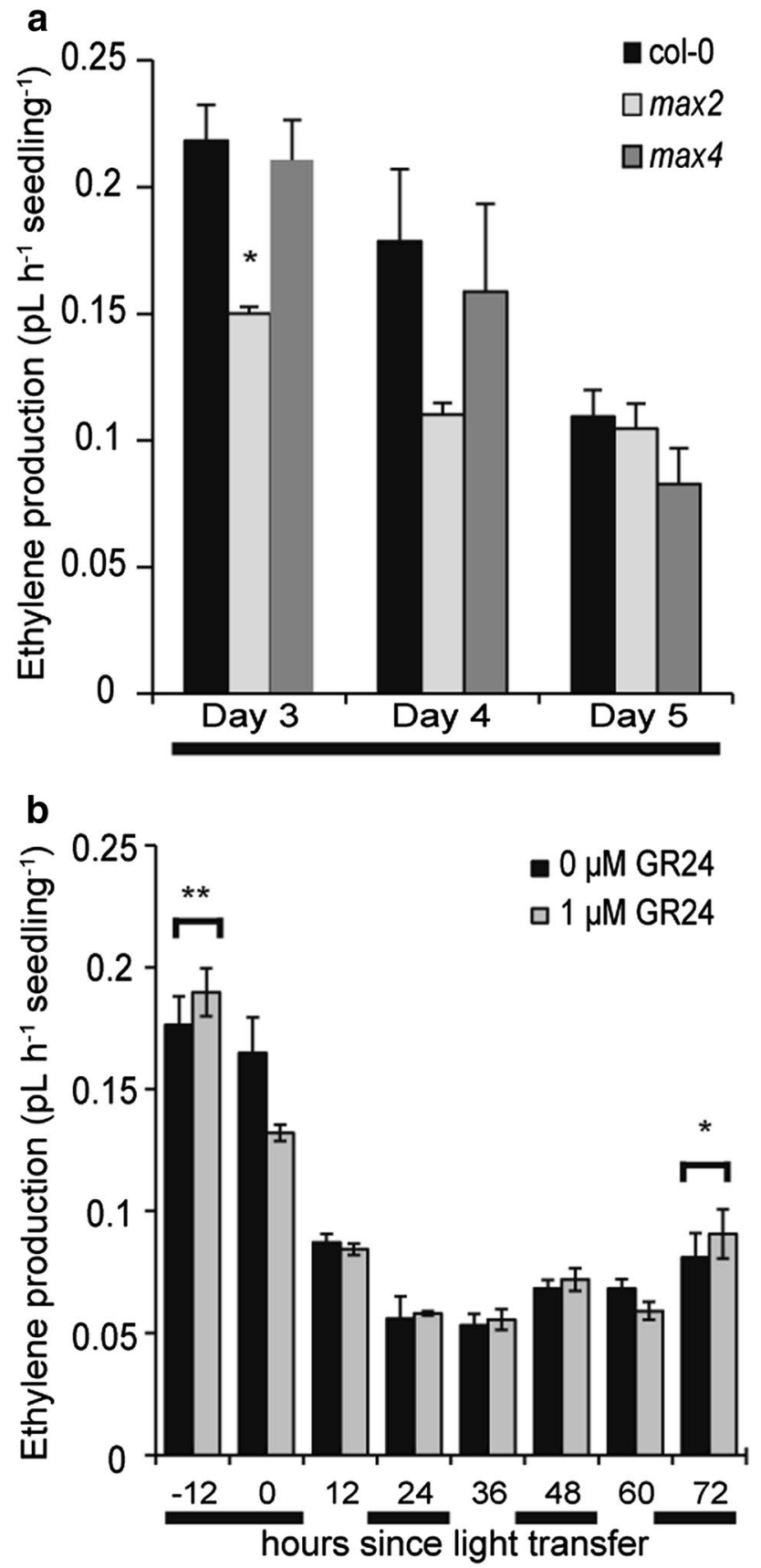

Fig. 2 Ethylene production is reduced in $\max 2$ strigolactone-insensitive mutant but unchanged by GR24 treatment or $\max 4$. a Ethylene production of etiolated Columbia wild-type, $\max 2$ strigolactoneinsensitive, and max4 strigolactone-deficient mutants after 3, 4, or 5 days of darkness. b Ethylene production of wild-type seedlings in the presence or absence of $1 \mu \mathrm{M}$ GR24. Measurements were taken $12 \mathrm{~h}$ before transfer to the light $(-12)$, transfer to the light $(0)$, and then every $12 \mathrm{~h}$ after transfer to the light $(12,24,36,48,60$, and $72 \mathrm{~h}$ since light transfer). The total etiolation was 4 days. Day length was $16 \mathrm{~h}$. a, $\mathbf{b}$ The periods of dark growth are indicated with black bars; night periods in (b) occurred from hrs 16-24; 40-48; and 64-72. Means are presented + standard error bars. Statistical comparison of average ethylene production (for (a) between $\max 2$ and wild type; (b) between untreated and GR24-treated for each time point) with Students $t$ test; $* P<0.05 ; * * P<0.01$ inhibition of elongation was observed from $0.1 \mu \mathrm{M}$ ACC, indicating that ACC stock activity was normal. In addition, the max4 mutant hypocotyl was $2 \mathrm{~mm}$ shorter than the wild type in control conditions. However, this reduction was very small compared to the effect on the hypocotyl length of ACC treatments or in enhanced ethylene signaling mutants.

Observation of the etiolated seedlings with adventitious roots revealed the typical reduction in root length in the presence of ACC (Fig. 1b). Moreover, a striking shift in the location of adventitious root formation to more apical positions was observed in all genotypes upon treatment with ACC (Fig. 1c-f). Therefore, the effect of ACC on the average number of adventitious roots was recorded separately for the top third and lower two-thirds of the hypocotyl to ensure that relevant ACC effects were not overlooked (Fig. 1g, h; also presented as a percentage of the total adventitious roots formed including seedlings where 0 roots formed in Supplemental Fig. 2a, b). ACC clearly enhanced the number (Fig. 1g) or percentage (Supplemental Fig. 2a) of adventitious roots in the apical third of the hypocotyl while reducing the number (Fig. $1 \mathrm{~h}$ ) or percentage (Supplemental Fig. 2b) of adventitious roots in the remaining part of the hypocotyl in both wild-type and $\max 2$ and $\max 4$ mutants. These results suggest that ethylene acts either downstream or independently of strigolactones in regulating adventitious root formation.

\section{Ethylene Production is Unchanged by GR24 Treatment or in the max4 Strigolactone Biosynthesis Mutant, but Reduced in the max2 Insensitive Mutant}

To determine if the strigolactone mutants produce different amounts of ethylene, emanation was measured from seedlings of Columbia wild type, $\max 2$, and $\max 4$ grown on control media (Fig. 2a). At 3, 4, and 5 days of etiolation, the ethylene production in max4 was not different from wild type (Fig. 2a). However at day 3 of etiolation, $\max 2$ produced significantly less ethylene $\left(0.15 \mathrm{pL} \mathrm{h}^{-1}\right.$ seedling $\left.{ }^{-1}\right)$ compared to the control seedlings $\left(0.22 \mathrm{pL} \mathrm{h}^{-1}\right.$ seedling ${ }^{-1}$; $P<0.01$; Fig. 2a). This trend was also apparent at 4 days of etiolation but was lost after 5 days of etiolated growth (Fig. 2a). This experiment has been repeated including $\max 1$ and $\max 3$ (other strigolactone biosynthesis mutants) and the pattern of ethylene production was consistent, with $\max 1, \max 3$, and $\max 4$ producing wild-type amounts of ethylene, while ethylene production in $\max 2$ was reduced (data not shown).

To determine if exogentableous strigolactone influences ethylene production, wild-type seedlings were grown in cuvettes either with control media or with $1 \mu \mathrm{M}$ of the synthetic strigolactone GR24. Ethylene emanation of etiolated seedlings was measured every $12 \mathrm{~h}$ starting at $12 \mathrm{~h}$ before 
the transition to light $(-12 \mathrm{~h})$ until $72 \mathrm{~h}$ after transition to light (Fig. 2b). After light transfer, no differences in ethylene production were found between the control and GR24treated seedlings, which is consistent with the results from GUS staining in the primary roots of the ethylene reporter EBS::GUS, where GR24 did not affect reporter gene induction (Supplemental Fig. 3; Stepanova and others 2007). After transfer to the light, ethylene production in both control and GR24-treated seedlings decreased from greater than $0.15 \mathrm{pL} \mathrm{h}^{-1}$ seedling ${ }^{-1}$ to about $0.05 \mathrm{pL} \mathrm{h}^{-1}$ seed$\operatorname{ling}^{-1}(P<0.01)$. Together, these findings suggest that ethylene production is influenced by MAX2 but does not require strigolactone.

\section{Ethylene Mutant Response to GR24 Treatments}

To determine if strigolactone acts upstream or downstream of ethylene in regulating adventitious root formation, we applied the synthetic strigolactone GR24 to a set of ethylene mutants (Fig. 3a, b). Because some of the mutants have shorter hypocotyls after etiolation, we standardized the number of adventitious roots as density (number of roots per mm of hypocotyl length) in Fig. 3a, whereas the total averages are presented in Fig. 3b. Ethylene mutants associated with enhanced ethylene sensitivity (ctrl-1) or production (eto2-1 and eto3-1) produced more adventitious roots per mm of hypocotyl compared to wild type (Fig. 3a). Similarly, the mutants associated with reduced sensitivity to ethylene (ein2-1, ein2-5, and ein3-1) produced less adventitious roots per mm compared to the wild type (Fig. 3a). The distribution of adventitious roots also varied across the different ethylene mutants. Comparable to Fig. 3a, b, both the average and standardized (density normalized to the length of the observed part of the hypocotyl) number of adventitious roots are presented. Less adventitious roots per $\mathrm{mm}$ were produced in the apical third of the hypocotyl for ein2-1 and ein2-5 (Fig. 3d, e; Supplemental Fig. 4a), whereas there was no strong evidence for a significant difference in the number and percentage of adventitious roots formed in the lower two-thirds of the hypocotyl (Fig. 3f, g; Supplemental Fig. 4b). On average, less adventitious roots were formed in the upper third of ctr1-1, eto2-1, and eto3-1 (Fig. 3e), but the density and percentages were unchanged compared to the wild type (Fig. 3d; Supplemental Fig. 4a). An increased density and a higher percentage of adventitious roots were observed in the lower two-thirds of ctrl1, eto2-1, and eto3-1 hypocotyls (Fig. 4f; Supplemental Fig. 4b), although there was no difference between the average numbers (Fig. 3e).

All mutants responded significantly to $1 \mu \mathrm{M}$ GR24 (Fig. 3a, b). When we look at percentage decreases, ctr1-1 seems to be less responsive than wild type ( $42 \%$ decrease in density compared to $68 \%$ decrease in wild type).
Furthermore, the ein2-1 mutant also responded in a dosedependent manner (Fig. 3c) with reductions of 35 and $87 \%$ in wild type and ein2-1, respectively, from doses as low as $1 \mathrm{nM}$ GR24.

In wild type, strigolactone inhibited adventitious root formation more in the top third of the hypocotyl (Fig. 3d, e). In ein 3-1, etr 1-1, and eto3-1, strigolactone also inhibited adventitious root formation of the top third of the hypocotyl (Fig. 3d, e). In the complete ethylene-insensitive mutants, ein2-1 and ein2-5, adventitious root formation was not significantly inhibited by strigolactone, which is probably due to the already low number of roots formed in control conditions. In ctrl-1 and eto2-1, adventitious root formation was not affected in the top third of the hypocotyl by strigolactone. Adventitious root formation was significantly inhibited by strigolactone in the lower two-thirds of the hypocotyl (Fig. 3f, g) for all genotypes. A similar trend can be observed for the percentage of adventitious roots in the lower two-thirds, although less pronounced (Supplemental Fig. 4b).

The hypocotyl lengths of ethylene-insensitive mutants (ein2-5, ein3-1, and etr1-1) were not significantly different from the wild type at the end of the experiment (Supplemental Fig. 5), whereas the constitutive ethylene mutants and overproducers (ctrl-1, eto2-1, and eto3-1) all had shorter hypocotyls (Supplemental Fig. 5).

The finding that the ethylene mutants respond to strigolactone demonstrates that strigolactones do not act upstream of ethylene in regulating adventitious root formation.

\section{Strigolactones Applied Together with ACC has an Additive Effect on Adventitious Root Formation}

To test whether strigolactones act independently of ethylene to regulate adventitious roots, we applied each hormone separately and together on wild type, $\max 2$, and max4. GR24 strongly inhibited adventitious root formation in both wild type and $\max 4$ but not in $\max 2$ (Fig. 4a) consistent with previous findings (Rasmussen and others 2012a). Similarly, high concentrations $(\geq 10 \mu \mathrm{M})$ of ACC reduced the total number of adventitious roots in $\max 2$ and $\max 4$ (Fig. 4a). When $1 \mu \mathrm{M}$ GR24 was applied together with either 10 or $100 \mu \mathrm{M}$ ACC, adventitious root formation was not significantly changed in $\max 2$ compared to the ACC treatment alone, whereas wild type and $\max 4$ were significantly reduced (Fig. 4a).

When the different zones of the hypocotyl were separated (Fig. 4b, c; Supplemental Fig. 6a, b), GR24 reduced the effect of ACC. GR24 alone still inhibited adventitious roots in wild type and max4, whereas 10 and $100 \mu \mathrm{M}$ ACC applied alone enhanced the number and percentage of adventitious roots in the top third of the hypocotyl (Fig. 4b and Supplemental Fig. 6a). When GR24 and ACC 


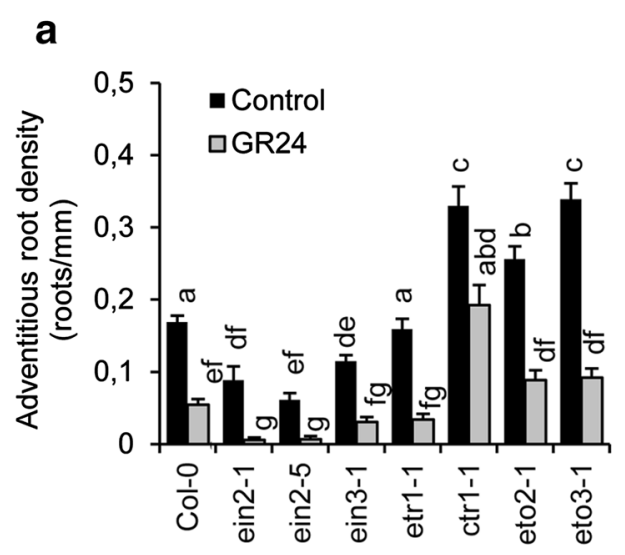

\section{b}

C

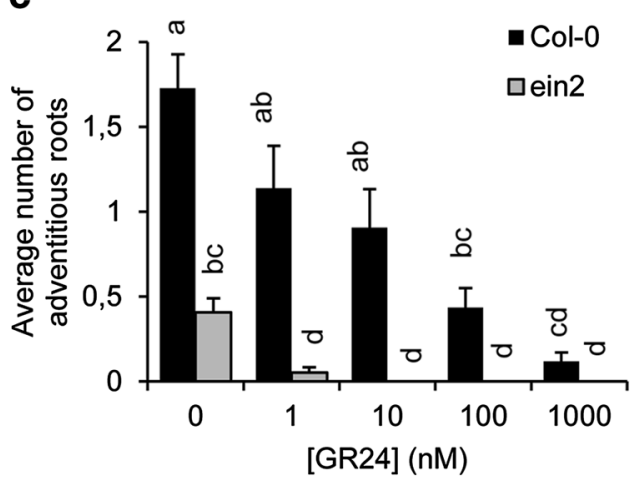

e

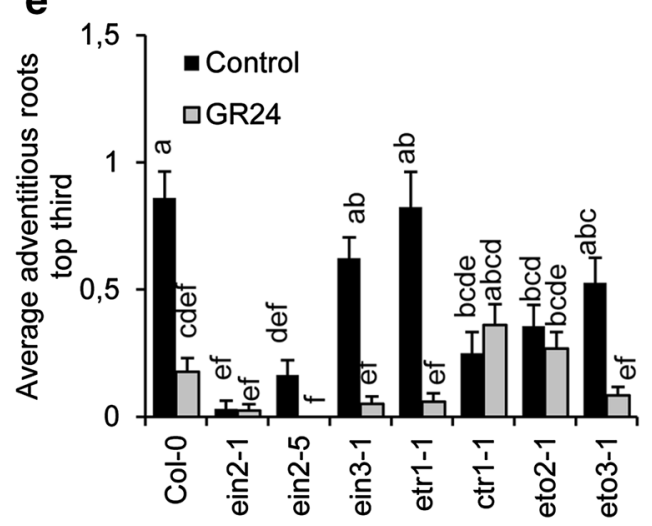

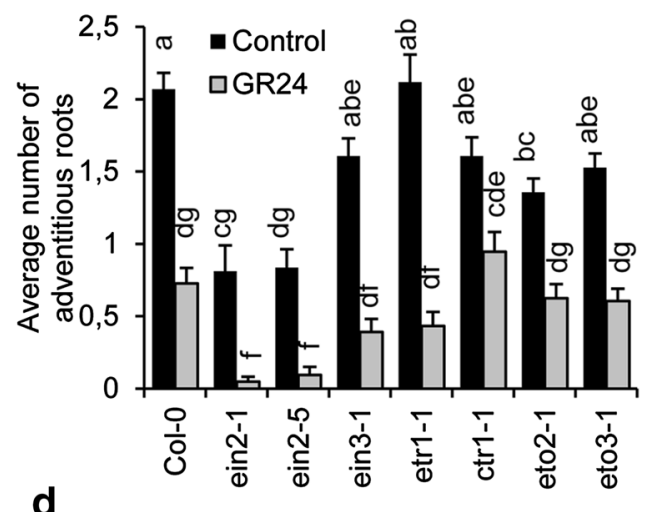

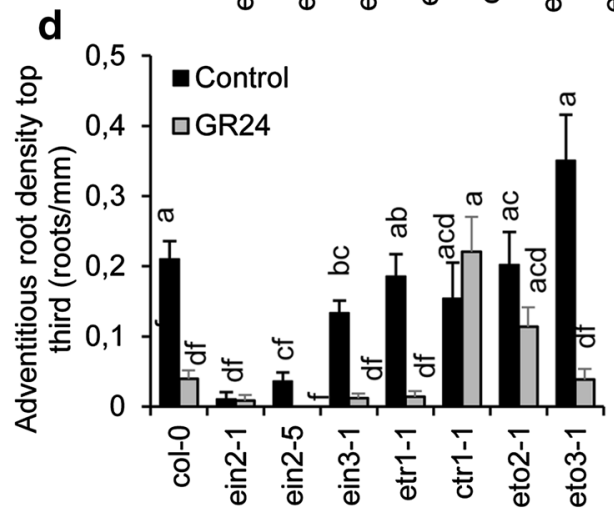

f

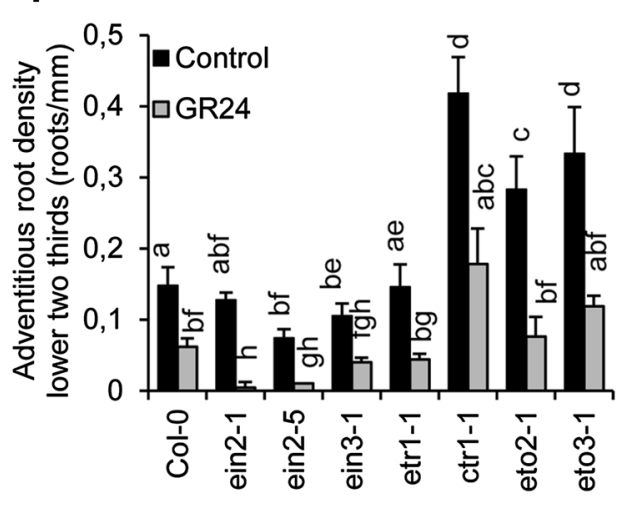

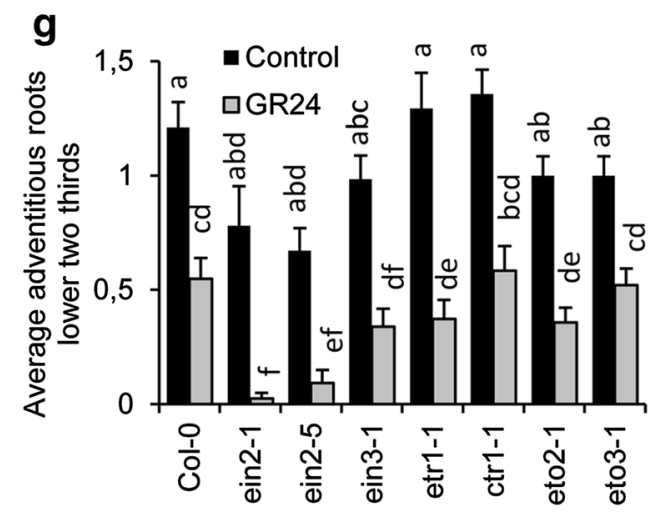


4Fig. 3 Synthetic strigolactone (GR24) reduced adventitious rooting in etiolated wild-type and ethylene mutants. a The number of adventitious roots presented per $\mathrm{mm}$ of etiolated hypocotyl because some mutants have reduced etiolated hypocotyl length. b The average number of adventitious roots per seedling in each of the ethylene mutants. c ein2 ethylene-insensitive mutant and Columbia wild type (col) treated with increasing doses of the synthetic strigolactone GR24. d The number of adventitious roots per mm of etiolated hypocotyl (top third) and $\mathbf{e}$ average number of adventitious roots emerging from top third of the hypocotyl of each of the mutants. $\mathbf{f}$ Density and $\mathbf{g}$ average of adventitious roots in the lower two-thirds of the hypocotyl for each of the mutants. Ethylene-insensitive mutants =ein2-1, ein2-5, ein3, etr1-1; Enhanced ethylene response mutants =ctr1-1; Ethylene overproducers mutants $=$ eto2-1, eto3-1. Means are presented \pm standard error. Different letters represent means that are significantly different. Statistical analysis through Scheirer-Ray-Hare test $(P<0.05)$ followed by post hoc Wilcoxon rank sum test $(P<0.05)(n>30$ per biological repeat, five biological repeats)

were applied together, the number of adventitious roots was enhanced in max 2 compared to wild type and reduced significantly in wild type and max4 compared to the ACC treatment alone. However, the promotive effect of high concentrations of ACC on adventitious root formation in GR24-treated wild-type and max4 seedlings was clearly visible compared to GR24 alone.

In the lower two-thirds of the hypocotyl (Fig. 4c and Supplemental Fig. 6b), 10 and $100 \mu \mathrm{M}$ ACC reduced the number and percentage of adventitious roots, while GR24 only inhibited the average number of adventitious roots in wild type and max4 but not the percentages. When GR24 was applied together with $10 \mu \mathrm{M}$ ACC, the percentage of adventitious roots in the lower two-thirds tended to increase compared to ACC alone. At high doses of ACC $(100 \mu \mathrm{M})$ this trend was less visible.

These findings suggest there are differences in response between the two regions of the hypocotyl. In the top third of the hypocotyl, ACC and GR24 have antagonistic roles in adventitious root formation, with ACC as an enhancer for adventitious root production, whereas GR24 reduces the ACC effect, resulting in intermediate numbers of adventitious roots. Conversely, in the lower part of the hypocotyl, both ACC and GR24 affect the number of adventitious roots negatively. However, GR24 appeared to be less effective in the lower thirds, compared to the top third. The effect of GR24 and ACC (particularly in the top third) supports the hypothesis that strigolactones and ethylene act independently to regulate adventitious root formation.

\section{Discussion}

We have demonstrated that ethylene and strigolactone both regulate adventitious root formation but in different ways and most likely act largely independently. The effect of ethylene on changing the distribution of adventitious roots, not seen for strigolactone, the antagonistic effect of ACC and GR24 in the top third of the hypocotyl, the response of strigolactone mutants to ACC, and the response of ethylene mutants to GR24 all support independent roles for strigolactones and ethylene. Furthermore, in preliminary experiments, GR24 had no effect on adventitious root formation if applied after the transition to the light (data not shown), while ACC still affects adventitious root formation at this time further supporting their independent roles in regulating adventitious root formation. This is seemingly in contrast to the interaction proposed between ethylene and exogenous strigolactones for regulating root hairs. However, it should be noted that strigolactone response mutants do not display a root hair phenotype (Kapulnik and others 2011b). It is possible that the interaction is specific for epidermal cells and it will be interesting in the future to know if primary root growth, lateral root formation, or nodulation is also regulated independently by strigolactones and ethylene.

Although the strigolactone mutants all respond to treatments with ACC, in some situations max2 appears to be more sensitive than the wild type (Fig. 1a). This increased sensitivity to ethylene may result in down-regulation of ethylene production via a feedback loop at lower levels of ethylene compared to the wild type and may explain the lower level of ethylene emanation observed for $\max 2$ (Fig. 2a). In addition, it has been shown in mung bean hypocotyls that ethylene inhibits adventitious root formation at higher auxin levels but promotes adventitious root formation at lower auxin levels (De Klerk and Hanecakova 2008). Since the strigolactone mutants have been reported to have enhanced auxin transport (Bennett and others 2006; Crawford and others 2010; Shen and others 2012), this may explain the relatively larger inhibition of adventitious rooting seen in strigolactone mutants. MAX2 has also been reported as a cross point in several other signaling networks including light responses (Shen and others 2007, 2012), karrikins (Nelson and others 2011), nodulation (Foo and others 2013), and light-grown hypocotyl elongation (Stirnberg and others 2002; Shen and others 2012). More recently, it was shown that auxin transport inhibition by NPA could rescue the long hypocotyl phenotype of $\max 2$ (Shen and others 2012). This does not rule out the possibility that ethylene regulation of auxin transport may be involved in this elongated hypocotyl. In addition, the study of the $d 14$ mutant, which appears to be specifically involved in strigolactone perception, might further elucidate hormonal cross talk or independence during adventitious rooting.

The slight enhancement of adventitious root formation in wild-type seedlings treated with low doses of ACC matches the phenotype of ethylene mutants with enhanced ethylene production or signaling. However, higher doses of ACC contrast with the ethylene mutant studies. Higher 
Fig. 4 Strigolactone and ACC treatments act independently on adventitious root formation in etiolated seedlings. In all, GR24 $=1 \mu \mathrm{M}$ synthetic strigolactone, $10 \mathrm{ACC}=10 \mu \mathrm{M}$ ACC; 100 $\mathrm{ACC}=100 \mu \mathrm{M}$ ACC; applied alone (controls) or together with $1 \mu \mathrm{M}$ GR24 (GR + ACC10 or GR + ACC100); col=Columbia wild type; $\max 2=$ strigolactone-insensitive mutant; $\max 4=$ strigolactone production mutant. a Average number of adventitious roots along the entire hypocotyl. b Average number of adventitious roots in the top third of the hypocotyl. c Average number of adventitious roots on the lower two-thirds of the hypocotyl. Means are presented \pm standard errors. Different letters represent means that are significantly different. Statistical analysis through Scheirer-Ray-Hare test $(P<0.05)$ followed by post hoc Wilcoxon rank sum test $(P<0.05)(n>30,2$ biological repeats)

levels of ACC in the media may enhance ethylene production indiscriminately throughout the tissue of the seedlings, whereas tissue-specific gradients may be important. This may also explain why the distribution of adventitious roots differed in the ethylene mutants where changes may occur in a tissue/cell-specific manner, compared to ubiquitous treatments with mobile signals.

Nonetheless, it is clear that a functional ethylene signaling machinery is necessary for adventitious root formation since ein 2 and ein 3 had significantly reduced adventitious root formation compared to wild type which also supports the enhanced adventitious root formation at low ACC concentrations. Other studies have also reported less adventitious roots in ethylene-insensitive mutants of tobacco (40\% reduction; McDonald and Visser 2003) and tomato (about $50 \%$ reduction; Negi and others 2010) in the absence of exogenous ethylene, whereas ethylene treatments decreased the number of adventitious roots in tobacco (McDonald and Visser 2003) in agreement with our findings with higher ACC treatments in Arabidopsis.

In addition to the adventitious root formation response to ethylene in Arabidopsis, this study demonstrates a differential distribution in adventitious root initiation along the etiolated hypocotyl of Arabidopsis. The effect of ACC treatment suggests that there are different zones within the hypocotyl, an upper zone (containing shorter cells) and the lower zone (containing elongated cells), with a different physiology (Supplemental Fig. S7). This is reminiscent of other processes, such as elongation, photoperception, or pigment accumulation, that are specifically active in the upper part of the hypocotyl (Gendreau and others 1997; Le and others 2005; Preuten and others 2013; Hatlestad and others 2015). Interestingly, the ethylene-induced shift is especially visible in the case of permanent high ethylene levels caused by exogenous ACC (Fig. 1; McDonnell and others 2009). The fact that enhanced ethylene-sensitive or ethylene-overproducing mutants do not show this response (Fig. 3) may be due to tissue-specific effects, which cannot be mimicked by administration of ACC in the medium. Adventitious roots in the upper zone respond positively to
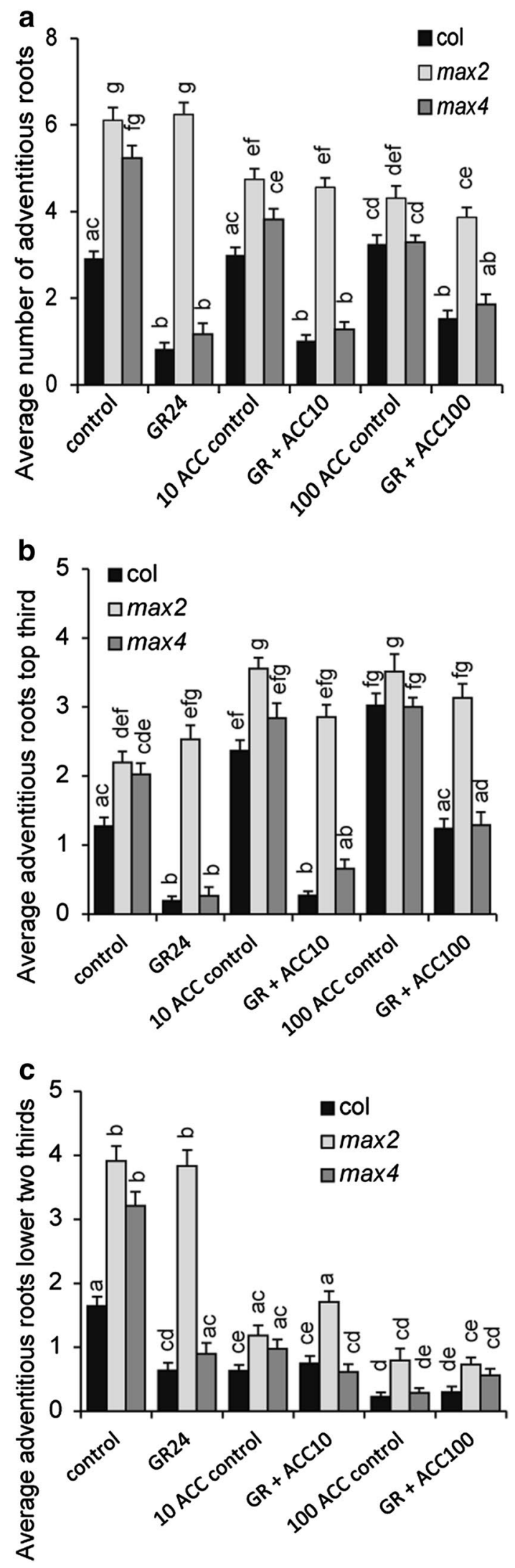
ACC but negatively to GR24, whereas adventitious roots in the lower zone respond negatively to both ACC and GR24. In contrast to our findings, adventitious root formation in sunflower cuttings form only on the lower section of the hypocotyl where ethylene promoted adventitious roots, whereas in the upper region ethylene inhibited adventitious root formation (Liu and others 1990). The difference may be species-specific, due to interactions with the wound response occurring in the sunflower cuttings or may be due to the loss of interactions with root-derived messages such as cytokinins. However, it does highlight the importance of positional effects along the hypocotyl. In Columbia wild type, the top third of the hypocotyl contains nearly half of the total cells in the length of the hypocotyl (Supplemental Fig. S7). These much shorter cells include the region which was the apical hook and these different zones of the hypocotyl have also been reported previously in terms of cell elongation. Goto and Esashi (1974) found that ethylene promoted cell elongation in the straight section of the hypocotyl, but inhibited elongation in the curved apical hook. Hypocotyl elongation is also more strongly inhibited by light in the top half of the hypocotyl and can be rescued by exogenous ACC but not auxin (Le and others 2005). Indeed, the top half of the hypocotyl has its own regulatory modules that lead to specific responses, for instance, involving auxin (Kami and others 2014) or light regulation of anthocyanin (Wang and others 2012). Other hormones were also demonstrated to have opposing effects in these two zones of the hypocotyl across several species (Schilmiller and Howe 2005; Ahkami and others 2009; Da Costa and others 2013). Our findings indicate that the hypocotyl is not only separated in different zones by their differences in cellular elongation responses as reported by others, but also have different properties in terms of developmental control of adventitious root formation.

The enhanced adventitious rooting of the upper zone of the hypocotyl by ACC may result from changes in PIN localization and/or function (Zadnikova and others 2010). Because there are more cells in the top third of the hypocotyl, this means there are more places to block auxin transport. In these upper cells, enough auxin may still build up and reach the threshold required to induce adventitious roots; however, inhibition of auxin transport may result in insufficient auxin to induce adventitious roots lower down the hypocotyl. This theory is also supported by an accumulation of auxin in the top of the hypocotyl which was also suggested to be due to a decrease in basipetal auxin transport (Vandenbussche and others 2010). Coincidentally, AUX1 and LAX3, which are crucial for adventitious root development (Dello Rovere and others, 2013), are associated with the ethylene-induced difference in auxin distribution in the hypocotyl (Vandenbussche and others 2010). Likewise, an AUX1- and LAX3-dependent ethylene effect on adventitious rooting was recently documented (Veloccia and others 2016).

Strigolactone has also been demonstrated to regulate PIN-mediated auxin transport (Bennett and others 2006; Crawford and others 2010; Shen and others 2012) and our previous work could not rule out an interaction between strigolactones and auxin transport in regulating adventitious root formation (Rasmussen and others 2012a). It is possible that enhanced global auxin transport in the strigolactone mutants provides more auxin in the hypocotyl to reach the threshold required for adventitious root initiation. This auxin is still present in the upper cells if ethylene reduces auxin transport (Vandenbussche and others 2010) and may explain the enhanced effect of ACC treatment in strigolactone mutants. The difference in the timing of action between the two hormones may be that enhancing auxin transport requires more time than inhibiting auxin transport since increased biosynthesis may also occur to replace the removed auxin from the top of the polar auxin transport stream. Although changes in auxin transport (globally in strigolactone mutants and locally in the upper hypocotyl from ACC treatments) fit the current literature and may explain the different positioning of adventitious roots along the hypocotyl, further investigations are needed to confirm this model in adventitious root formation.

It is clear from our study that by scoring overall numbers of adventitious roots valuable physiological/phenotypic information can be lost. Since the overall number of adventitious roots did not change much, it could be suggested that ethylene does not have a strong effect on adventitious roots, and indeed depending on which concentration was applied could suggest that ethylene either slightly promotes or inhibits adventitious root formation. In contrast to the overall effect on root numbers, dissecting the distribution of adventitious roots demonstrated that ethylene has a dramatic effect on adventitious root formation. This may also partly explain the contradictory literature regarding the effect of ethylene on adventitious root formation. For example, in tomato ACC enhanced adventitious root formation at 1 and $10 \mu \mathrm{M}$ (Negi and others 2010), whereas in tobacco $2.1 \mu \mathrm{L} \mathrm{L}^{-1}$ ethylene treatments inhibited adventitious root formation (McDonald and Visser 2003). In mung bean, ethylene both promoted and inhibited adventitious rooting depending on the auxin status of the seedlings (De Klerk and Hanecakova 2008). By studying the distribution of adventitious roots, interactions between ethylene and other hormones may become clearer, such as demonstrated here for strigolactones.

Ethylene is also implicated in flooding-induced adventitious roots (Wample and Reid 1978). In deep-water rice, it was shown that the increase in adventitious root emergence with waterlogging followed a similar time course and magnitude to ethylene treatments (Lorbiecke and Sauter 
1999). The ethylene-insensitive tobacco mutant Tetr was less responsive to waterlogging compared to the wild type (McDonald and Visser 2003). Furthermore, when ethylene production was inhibited using L- $\alpha$-(2-aminoethoxyvinyl)glycine (AVG) in flooded Rumex sp, the number of adventitious roots was decreased (Visser and others 1996). Despite the role of adventitious roots in flooding tolerance and the link between waterlogging and ethylene production, the positioning of these roots is rarely reported. It makes sense for submerged plants to produce adventitious roots as close to the top as possible to help reduce the hypoxia inhibition of growth. Hypoxia has been shown to enhance ethylene production (Geisler-Lee and others 2010) and conversion of ACC to ethylene requires oxygen and so will be greater from the water surface. This may then encourage adventitious root development close to the surface. However, further experiments using flooding will be required to demonstrate this role for ethylene-regulated distribution of adventitious roots and may help improve flooding tolerance in important crop species.

Building on the model in Rasmussen and others (2012a), and published data showing the close interaction between ethylene and auxin (Vandenbussche and others 2012), we have added the role of ethylene in adventitious root formation in intact Arabidopsis hypocotyls (Fig. 5). In the model, strigolactones inhibit adventitious root formation, possibly via changes in auxin transport. Strigolactones and ethylene converge on the regulation of auxin distribution

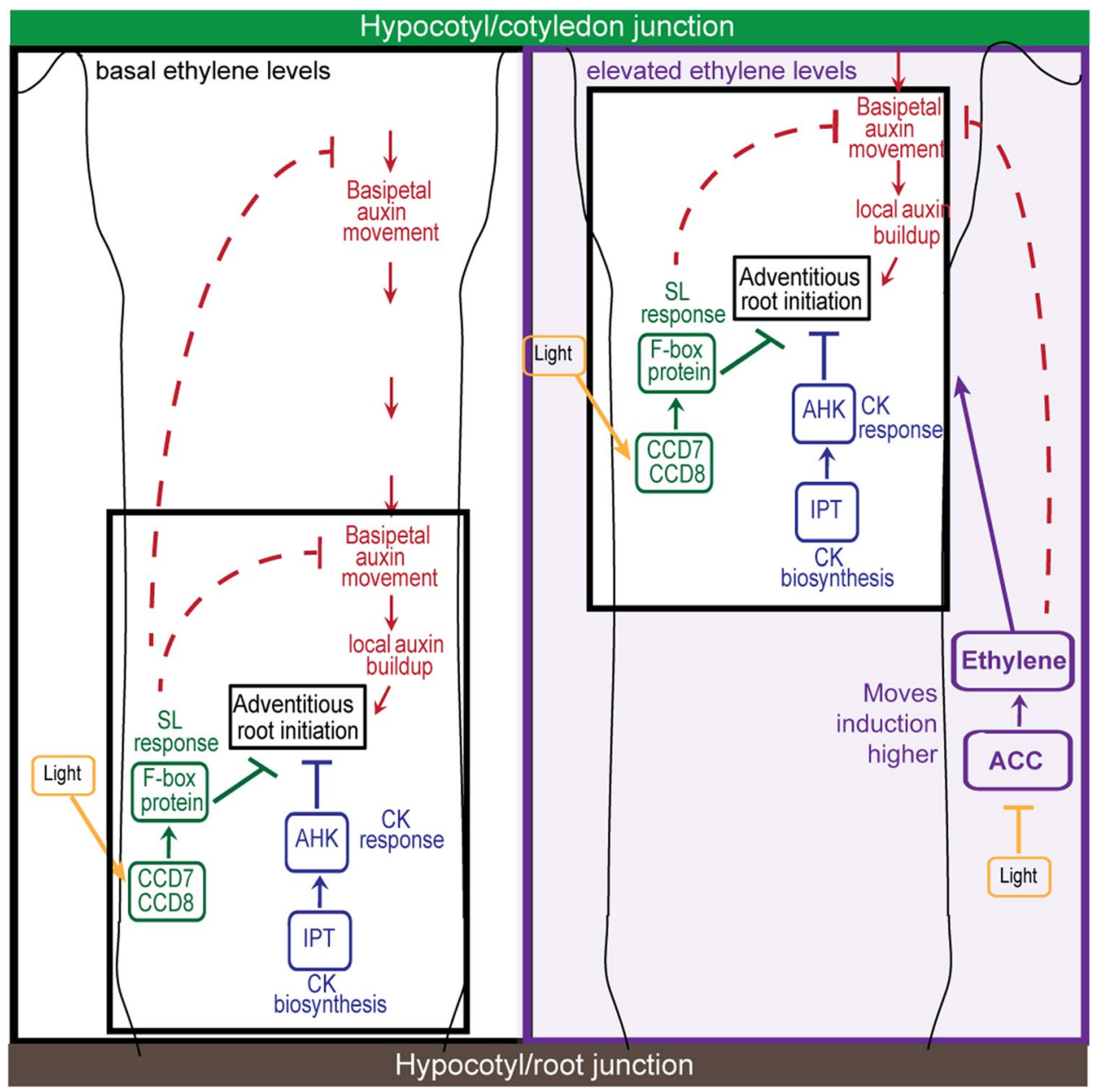

Fig. 5 Model of adventitious root formation in etiolated seedlings. Built on model in Rasmussen and others (2012a). Solid lines represent demonstrated pathways, whereas dashed lines represent inconclusive pathways. Arrows represent promotion and flat-ended lines represent repression. Strigolactone production occurs via $C C D 7$ and CCD8 genes and response requires F-box protein (Gomez-Rolden and others 2008; Umehara and others 2008). Inhibition of adventitious root initiation by strigolactone may occur directly or via auxin transport (dashed lines here, Rasmussen and others 2012a). Cyto- kinins were also shown to be independent of strigolactones in (Rasmussen and others 2012a). Light promoted CCD7 and CCD8 expression (Rasmussen and others 2012a) and inhibited ethylene production in etiolated seedlings (Fig. 2b). Ethylene applications moved adventitious root initiation sites to higher up the hypocotyl possibly via the inhibition of auxin transport (Preuten and others 2013; Vandenbussche and others 2010) (represented by curved dashed inhibitory lines), whereas under normal ethylene conditions adventitious roots can form anywhere along the hypocotyl 
and responses. In addition cytokinin acts independently of strigolactones to inhibit adventitious root formation (Rasmussen and others 2012a). From the results in this study, ethylene moves the location of adventitious root formation to higher positions on the hypocotyl. It will be of interest to evaluate whether this model applies to other systems often used in a horticultural context, such as wounded hypocotyls, excised leaves, or stem cuttings.

Acknowledgements Open access funding provided by University of Nottingham. YH, TD, FV, and DVDS thank Katrien Haustraete for technical assistance. DVDS acknowledges Dr. J.R Ecker (The Salk Institute, USA) for providing the EBS::GUS 1-11. All authors acknowledge I. Verstraeten's support and discussions. AR thanks FP7 Marie Curie International Incoming Fellowships, Newton International Fellowships, and Nottingham Research Fellowships. DVDS and DG gratefully acknowledge the Research Foundation-Flanders (FWO) for financial support (3G030612). FV performed part of this work as post-doctoral fellow of the Research Foundation-Flanders (FWO).

Authors' contributions AR conceived the study, carried out all experiments in Fig. 1,3, 4, and 5 and Supplemental Figures S1, S2, S4, S5, S6, S7, drafted, and helped in editing the manuscript. YH carried out ethylene measurements in Fig. 2 and Supplemental Fig S3. TD performed the statistical analysis and assisted in rewriting the sections of the results and discussion of the manuscript. FDB provided valuable resources. FV assisted in rewriting the sections of the discussion. FV, DVDS, and DG assisted in coordination and discussion of results, particularly regarding ethylene measurements and assisted in editing the manuscript. All authors read and approved the final manuscript.

\section{Compliance with Ethical Standards}

Conflict of interest The authors declare that we have no competing interests.

Open Access This article is distributed under the terms of the Creative Commons Attribution 4.0 International License (http:// creativecommons.org/licenses/by/4.0/), which permits unrestricted use, distribution, and reproduction in any medium, provided you give appropriate credit to the original author(s) and the source, provide a link to the Creative Commons license, and indicate if changes were made.

\section{References}

Achard P, Cheng H, De Grauwe L, Decat J, Schoutteten H, Moritz T, Van Der Straeten D, Peng J, Harberd NP (2006) Integration of plant responses to environmentally activated phytohormonal signals. Science 311(5757):91-94. doi:10.1126/science.1118642

Ahkami AH, Lischewski S, Haensch K-T, Porfirova S, Hofmann J, Rolletschek H, Melzer M, Franken P, Hause B, Druege U, Hajirezaei MR (2009) Molecular physiology of adventitious root formation in Petunia hybrida cuttings: involvement of wound response and primary metabolism. New Phytol 181(3):613-625. doi:10.1111/j.1469-8137.2008.02704.x
Akiyama K, Matsuzaki K, Hayashi H (2005) Plant sesquiterpenes induce hyphal branching in arbuscular mycorrhizal fungi. Nature 435:824-827. doi:10.1038/nature03608

Arite T, Umehara M, Ishikawa S, Hanada A, Maekawa M, Yamaguchi S, Kyozuka J (2009) d14, a strigolactone-insensitive mutant of rice, shows an accelerated outgrowth of tillers. Plant Cell Physiol 50(8):1416-1424. doi:10.1093/pcp/pcp091

Bennett T, Sieberer T, Willett B, Booker J, Luschnig C, Leyser O (2006) The Arabidopsis MAX pathway controls shoot branching by regulating auxin transport. Curr Biol 16:553-563. doi:10.1016/j.cub.2006.01.058

Beveridge CA, Kyozuka J (2010) New genes in the strigolactonerelated shoot branching pathway. Curr Opin Plant Biol 13(1):3439. doi:10.1016/j.pbi.2009.10.003

Biondi S, Diaz T, Iglesias I, Gamberini G, Bagni N (1990) Polyamines and ethylene in relation to adventitious root formation in Prunus avium shoot cultures. Physiol Plant 78(3):474-483. doi:10.1111/j.1399-3054.1990.tb09066.x

Booker J, Sieberer T, Wright W, Williamson L, Willett B, Stirnberg P, Turnbull C, Srinivasan M, Goddard P, Leyser O (2005) MAX1 encodes a cytochrome P450 family member that acts downstream of MAX3/4 to produce a carotenoid-derived branchinhibiting hormone. Dev Cell 8(3):443-449. doi:10.1016/j. devcel.2005.01.009

Chae HS, Faure F, Kieber JJ (2003) The eto1, eto2, and eto3 mutations and cytokinin treatment increase ethylene biosynthesis in Arabidopsis by increasing the stability of ACS protein. Plant Cell 15(2):545-559. doi:10.1105/tpc.006882

Cook CE, Whichard LP, Turner B, Wall ME (1966) Germination of witchweed (Striga lutea lour)-isolation and properties of a potent stimulant. Science 154:1198-6199. doi:10.1126/ science.154.3753.1189

Crawford S, Shinohara N, Sieberer T, Williamson L, George G, Hepworth J, Muller D, Domagalska MA, Leyser O (2010) Strigolactones enhance competition between shoot branches by dampening auxin transport. Development 137:2905-2913. doi:10.1242/ dev.051987

Da Costa CT, De Almeida MR, Ruedell CM, Schwambach J, Maraschin FDS, Fett-Neto AG (2013) When stress and development go hand in hand: Main hormonal controls of adventitious rooting in cuttings. Front Plant Sci 4:1-19. doi:10.3389/fpls.2013.00133

De Klerk G-J, Hanecakova J (2008) Ethylene and rooting of mung bean cuttings. The role of auxin induced ethylene synthesis and phase-dependent effects. J Plant Growth Regul 56(2):203-209. doi:10.1007/s10725-008-9301-8

De Paepe A, Van Der Straeten D (2005) Ethylene biosynthesis and signaling: an overview. Vitam Horm 72:399-430. doi:10.1016/ S0083-6729(05)72011-2

De Klerk GJ, Van der Krieken W, De Jong JC (1999) Review-The formation of adventitious roots: New concepts, new possibilities. In Vitro Cell Dev Biol-Plant 35(3):189-199. doi:10.1007/ s11627-999-0076-Z

de Saint Germain A, Bonhomme S, Boyer F-D, Rameau C (2013) Novel insights into strigolactone distribution and signalling. Curr Opin Plant Biol 16(5):583-589. doi:10.1016/j.pbi.2013.06.007

Della Rovere F, Fattorini L, D’Angeli S, Veloccia A, Falasca G, Altamura MM (2013) Auxin and cytokinin control formation of the quiescent centre in the adventitious root apex of Arabidopsis. Ann Bot 112:1395-1407. doi:10.1093/aob/mct215

Drummond RSM, Martinez-Sanchez NM, Janssen BJ, Templeton KR, Simons JL, Quinn BD, Karunairetnam S, Snowden KC (2009) Petunia hybrida CAROTENOID CLEAVAGE DIOXYGENASE7 is involved in the production of negative and positive branching signals in petunia. Plant Physiol 151(4):1867-1877. doi:10.1104/pp.109146720 
Ellison CT, Vandenbussche F, Van Der Straeten D, Harmer SL (2011) XAP5 CIRCADIAN TIMEKEEPER regulates ethylene responses in aerial tissues of Arabidopsis. Plant Physiol 155(2):988-999. doi:10.1104/pp.110.164277

Foo E, Yoneyama K, Hugill CJ, Quittenden LJ, Reid JB (2013) Strigolactones and the regulation of pea symbioses in response to nitrate and phosphate deficiency. Mol Plant 6(1):76-87. doi: $10.1093 / \mathrm{mp} / \mathrm{sss} 115$

Geisler-Lee J, Caldwell C, Gallie DR (2010) Expression of the ethylene biosynthetic machinery in maize roots is regulated in response to hypoxia. J Exp Bot 61(3):857-871. doi:10.1093/jxb/ erp362

Gendreau E, Traas J, Desnos T, Grandjean O, Caboche M, Hofte (1997) Cellular Basis of Hypocotyl Growth in Arabidopsis thaliana. Plant Physiol 114(1):295-305 doi:10.1104/pp.114.1.295

Gomez-Rolden V, Fermas S, Brewer PB, Puech-Pages V, Dun EA, Pillot J-P, Letisse F, Matusova R, Danoun S, Portais J-C, Bouwmeester H, Becard G, Beveridge CA, Rameau C, Rochange SF (2008) Strigolactone inhibition of shoot branching. Nature 455(7210):189-194. doi:10.1038/nature07271

Goto N, Esashi Y (1974) Stimulation by ethylene of axis and hypocotyl growth in bean and cocklebur seedlings. Physiol Plant 31(3):204-210. doi:10.1111/j.1399-3054.1974.tb03692.x

Hamiaux C, Drummond RS, Janssen BJ, Ledger SE, Cooney JM, Newcomb RD, Snowden KC (2012) DAD2 is an $\alpha / \beta$ hydrolase likely to be involved in the perception of the plant branching hormone, strigolactone. Curr Biol 22(21):2032-2036. doi:10.1016/j. cub.2012.08.007

Harbage JF, Stimart DP (1996) Effect of pH and 1 H-indole-3-butyric acid (IBA) on rooting of apple microcuttings. J Am Soc Hortic Sci 121(6):1049-1053

Hatlestad GJ, Akhavan NA, Sunnadeniya RM, Elam L, Cargile S, Hembd A, Gonzalez A, McGrath JM, Lloyd AM (2015) The beet $\mathrm{Y}$ locus encodes an anthocyanin MYB-like protein that activates the betalain red pigment pathway. Nat Genet 47(1):92-96. doi:10.1038/ng.3163

Ivanchenko MG, Muday GK, Dubrovsky JG (2008) Ethyleneauxin interactions regulate lateral root initiation and emergence in Arabidopsis thaliana. Plant J 55(2):335-347. doi:10.1111/j.1365-313X.2008.03528.x

Kagiyama M, Hirano Y, Mori T, Kim SY, Kyozuka J, Seto Y, Yamaguchi S, Hakoshima T (2013) Structures of D14 and D14L in the strigolactone and karrikin signaling pathways. Genes Cells 18(2):147-160. doi:10.1111/gtc. 12025

Kami C, Allenbach L, Zourilidou M, Ljung K, Schutz F, Isono E, Watahiki MK, Yamamoto KT, Schwechheimer C, Fankhauser C (2014) Reduced phototropism in pks mutants may be due to altered auxin-regulated gene expression or reduced lateral auxin transport. Plant J 77(3):393-403. doi:10.1111/tpj.12395

Kapulnik Y, Delaux PM, Resnick N, Mayzlish-Gati E, Wininger S, Bhattacharya C, Sejalon-Delmas N, Combier JP, Becard G, Belausov E, Beeckman T, Dor E, Hershenhorn J, Koltai H (2011a) Strigolactones affect lateral root formation and root-hair elongation in Arabidopsis. Planta 233(1):209-216. doi:10.1007/s00425-010-1310-y

Kapulnik Y, Resnick N, Mayzlish-Gati E, Kaplan Y, Wininger S, Hershenhorn J, Koltai H (2011b) Strigolactones interact with ethylene and auxin in regulating root-hair elongation in Arabidopsis. J Exp Bot 62(8):2915-2924. doi:10.1093/jxb/erq464

Kilkenny AJ, Wallace HM, Walton DA, Adkins MF, Trueman SJ (2012) Improved root formation in Eucalypt cuttings following combined auxin and anti-ethylene treatments. J Plant Sci 7:138-153. doi:10.3923/jps.2012.138.153

Kohlen W, Charnikhova T, Lammers M, Pollina T, Tóth P, Haider I, Pozo MJ, de Maagd RA, Ruyter-Spira C, Bouwmeester HJ, Lopez-Raez JA (2012) The tomato CAROTENOID
CLEAVAGE DIOXYGENASE8 (SICCD8) regulates rhizosphere signaling, plant architecture and affects reproductive development through strigolactone biosynthesis. New Phytol 196(2):535-547. doi:10.1111/j.1469-8137.2012.04265.x

Koltai H, Dor E, Hershenhorn J, Joel DM, Weininger S, Lekalla S, Shealtiel H, Bhattacharya C, Eliahu E, Resnick N, Barg R, Kapulnik Y (2010) Strigolactones' effect on root growth and root-hair elongation may be mediated by auxin-efflux carriers. J Plant Growth Regul 29(2):129-136. doi:10.1007/ s00344-009-9122-7

Le J, Vandenbussche F, De Cnodder T, Van Der Straeten D, Verbelen JP (2005) Cell elongation and microtubule behavior in the Arabidopsis hypocotyl: responses to ethylene and auxin. J Plant Growth Regul 24(3):166-178. doi:10.1007/ s00344-005-0044-8

Lewis DR, Negi S, Sukumar P, Muday GK (2011) Ethylene inhibits lateral root development, increases IAA transport and expression of PIN3 and PIN7 auxin efflux carriers. Development 138(16):3485-3495. doi:10.1242/dev.065102

Liang JL, Zhao LJ, Challis R, Leyser O (2010) Strigolactone regulation of shoot branching in chrysanthemum (Dendranthema grandiflorum). J Exp Bot 61(11):3069-3078. doi:10.1093/jxb/erq133

Liu J-H, Mukherjee I, Reid DM (1990) Adventitious rooting in hypocotyls of sunflower (Helianthus annuus) seedlings. III. The role of ethylene. Physiol Plant 78:268-276. doi:10.1111/j.1399-3054.1990.tb02091.x

Logan DC, Stewart GR (1991) Role of ethylene in the germination of the hemiparasite Striga hermonthica. Plant Physiol 97:14351438 doi:10.1104/pp.97.4.1435

Lorbiecke R, Sauter M (1999) Adventitious root growth and cellcycle induction in deepwater rice. Plant Physiol 119:21-29 doi:10.1104/pp.119.1.21

Matusova R, Rani K, Verstappen FWA, Franssen MCR, Beale MH, Bouwmeester HJ (2005) The strigolactone germination stimulants of the plant-parasitic Striga and Orobanche spp. are derived from the carotenoid pathway. Plant Physiol 139:920-934. doi:10.1104/pp.105.061382

McDonald MP, Visser EJW (2003) A study of the interaction between auxin and ethylene in wild type and transgenic ethylene-insensitive tobacco during adventitious root formation induced by stagnant root zone conditions. Plant Biol 5(5):550-556. doi:10.105 5/s-2003-44790

McDonnell L, Plett JM, Andersson-Gunnerås S, Kozela C, Dugardeyn J, Van Der Straeten D, Glick BR, Sundberg B, Regan S (2009) Ethylene levels are regulated by a plant encoded 1-aminocyclopropane-1-carboxylic acid deaminase. Physiol Plant 136:94-109. doi:10.1111/j.1399-3054.2009.01208.x

Negi S, Sukumar P, Liu X, Cohen JD, Muday GK (2010) Genetic dissection of the role of ethylene in regulating auxin-dependent lateral and adventitious root formation in tomato. Plant J 61(1):315. doi:10.1111/j.1365-313X.2009.04027.x

Nelson DC, Scaffidid A, Dun EA, Waters MT, Flematti GR, Dixon KW, Beveridge CA, Ghisalberti EL, Smith SM (2011) F-Box protein MAX2 has dual roles in karrikin and strigolactone signaling in Arabidopsis thaliana. Proc Natl Acad Sci USA 108(21):8897-8902. doi:10.1073/pnas.1100987108

Preuten T, Hohm T, Bergmann S, Fankhauser C (2013) Defining the site of light perception and initiation of phototropism in Arabidopsis. Curr Biol 23(19):1934-1938. doi:10.1016/j. cub.2013.07.079

Qiao H, Shen Z, Huang S-SC, Schmitz RJ, Urich MA, Briggs SP, Ecker JR (2012) Processing and subcellular trafficking of ERtethered EIN2 control in response to ethylene gas. Science 338:390-393. doi:10.1126/science. 1225974 
Radin JW, Loomis RS (1969) Ethylene and carbon dioxide in the growth and development of cultured radish roots. Plant Physiol 44:1584-1589 doi:10.1104/pp.44.11.1584

Rasmussen A, Mason MG, Cuyper CD, Brewer PB, Herold S, Agusti J, Geelen D, Greb T, Goormachtig S, Beeckman T, Beveridge CA (2012a) Strigolactones suppress adventitious rooting in Arabidopsis and Pea. Plant Physiol 158:1-12. doi:10.1104/ pp.111.187104

Rasmussen A, Beveridge CA, Geelen D (2012b) Inhibition of strigolactones promotes adventitious root formation. Plant Signal Behav 7(6):694-697. doi:10.4161/psb.20224

Rasmussen A, Depuydt S, Goormachtig S, Geelen D (2013) Strigolactones fine-tune the root system. Planta 238:615-626. doi:10.1007/s00425-013-1911-3

Riov J, Yang SF (1989) Ethylene and auxin-ethylene interaction in adventitious root formation in mung bean (Vigna radiata) cuttings. J Plant Growth Regul 8(2):131-141. doi:10.1007/ BF02025280

Ruzicka K, Ljung K, Vanneste S, Podhorska R, Beeckman T, Friml J, Benkova E (2007) Ethylene regulates root growth through effects on auxin biosynthesis and transport-dependent auxin distribution. Plant Cell 19(7):2197-2212 doi:10.1105/tpc.107.052126

Schilmiller AL, Howe GA (2005) Systemic signaling in the wound response. Curr Opin Plant Biol 8(4):369-377. doi:10.1016/j. pbi.2005.05.008

Shen H, Luong P, Huq E (2007) The F-Box protein MAX2 functions as a positive regulator of photomorphogenesis in Arabidopsis. Plant Physiol 145:1471-1483. doi:10.1104/pp.107.107227

Shen H, Zhu L, Bu Q-Y, Huq E (2012) MAX2 affects multiple hormones to promote photomorphogenesis. Mol Plant 5(3):750762. doi: $10.1093 / \mathrm{mp} / \mathrm{sss} 029$

Smalle J, Haegman M, Kurepa J, Van Montagu M, Van Der Straeten D (1997) Ethylene can stimulate Arabidopsis hypocotyl elongation in the light. Proc Natl Acad Sci USA 94:2756-2761

Sorin C, Negroni L, Balliau T, Corti H, Jacquemot M-P, Davanture M, Sandberg G, Zivy M, Bellini C (2005) Proteomic analysis of different mutant genotypes of Arabidopsis led to the identification of 11 proteins correlating with adventitious root development. Plant Physiol 140:349-364. doi:10.1104/pp.105.067868

Stepanova AN, Yun J, Likhacheva AV, Alonso JM (2007) Multilevel interactions between ethylene and auxin in Arabidopsis roots. Plant Cell 19(7):2169-2185 doi:10.1105/tpc.107.052068

Stirnberg P, van de Sande K, Leyer HMO (2002) MAX1 and MAX2 control shoot lateral branching in Arabidopsis. Development 129:1131-1141.

Stirnberg P, Furner IJ, Leyser HMO (2007) MAX2 participates in an SCF complex which acts locally at the node to suppress shoot branching. Plant J 50(1):80-94. doi:10.1111/j.1365-313X.2007.03032.x

Sugimoto Y, Ali AM, Yabuta S, Kinoshita H, Inanaga S, Itai A (2003) Germination strategy of Striga hermonthica involves regulation of ethylene biosynthesis. Physiol Plant 119(1):137-145. doi:10.1034/j.1399-3054.2003.00162.x

Swarup R, Perry P, Hagenbeek D, Van Der Straeten D, Beemster GTS, Sandberg G, Bhalerao R, Ljung K, Bennett MJ (2007) Ethylene upregulates auxin biosynthesis in Arabidopsis seedlings to enhance inhibition of root cell elongation. Plant Cell 19(7):2186-2196 doi:10.1105/tpc.107.052100
Thain SC, Vandenbussche F, Laarhoven LJ, Dowson-Day MJ, Wang ZY, Tobin EM, Harren FJ, Millar AJ, Van Der Straeten D (2004) Circadian rhythms of ethylene emission in Arabidopsis. Plant Physiol 136(3):3751-3761. doi:10.1104/pp.104.042523

Umehara M, Hanada A, Yoshida S, Akiyama K, Arite T, TakedaKamiya N, Magome H, Kamiya Y, Shirasu K, Yoneyama K, Kyozuka J, Yamaguchi S (2008) Inhibition of shoot branching by new terpenoid plant hormones. Nature 455(7210):195-200. doi:10.1038/nature07272

Urquhart S, Foo E, Reid JB (2015) The role of strigolactones in photomorphogenesis of pea is limited to adventitious rooting. Physiol Plant 153(3):392-402. doi:10.1111/ppl.12246

Van de Poel B, Smet D, Van Der Straeten D (2015) Ethylene and hormonal cross talk in vegetative growth and development. Plant Physiol 169:61-72. doi:10.1104/pp.15.00724

Vandenbussche F, Petrasek J, Zadnikova P, Hoyerova K, Pesek B, Raz V, Swarup R, Bennett M, Zazimalova E, Benkova E, Van Der Straeten D (2010) The auxin influx carriers AUX1 and LAX3 are involved in auxin-ethylene interactions during apical hook development in Arabidopsis thaliana seedlings. Development 137(4):597-606. doi:10.1242/dev.040790.

Vandenbussche F, Vaseva I, Vissenberg K, Van Der Straeten D (2012) Ethylene in vegetative development: a tale with a riddle. New Phytol 194(4):895-909. doi:10.1111/j.1469-8137.2012.04100.x

Veloccia A, Fattorini L, Della Rovere F, Sofo A, D’Angeli S, Betti C, Falasca G, Altamura MM (2016) Ethylene and auxin interaction in the control of adventitious rooting in Arabidopsis thaliana. $\mathrm{J}$ Exp Bot. 67:6445-6458. doi:10.1093/jxb/erw415

Visser EJW, Bogemann GM, Blom CWPM, Voesenek LACJ (1996) Ethylene accumulation in waterlogged Rumex plants promotes formation of adventitious roots. J Exp Bot 296:403-410. doi:10.1093/jxb/47.3.403

Vriezen WH, Zhou Z, Van Der Straeten D (2003) Regulation of submergence-induced enhanced shoot elongation in Oryza sativa L. Ann Bot 91:263-270. doi:10.1093/aob/mcf121

Wample RL, Reid DM (1978) Control of adventitious root production and hypocotyl hypertrophy of sunflower (Helianthus annuus) in response to flooding. Physiol Plant 44:351-358. doi:10.1111/j.1399-3054.1978.tb01636.x

Wang Y, Zhou B, Sun M, Li Y, Kawabata S (2012) UV-A light induces anthocyanin biosynthesis in a manner distinct from synergistic blue + UV-B light and UV-A/Blue light responses in different parts of the hypocotyls in turnip seedlings. Plant Cell Physiol 53(8):1470-1480. doi:10.1093/pcp/pcs088

Woeste KE, Ye C, Kieber JJ (1999) Two Arabidopsis mutants that overproduce ethylene are affected in the posttranscriptional regulation of 1-aminocyclopropane-1-carboxylic acid synthase. Plant Physiol 119:521-530 doi:10.1104/pp.119.2.521

Yao R, Ming Z, Yan L, Li S, Wang F, Ma S, Yu C, Yang M, Chen L, Chen L, Li Y, Yan C, Miao D, Sun Z, Yan J, Sun Y, Wang L, Chu J, Fan S, He W, Deng H, Nan F, Li J, Rao Z, Lou Z, Xie D (2016) DWARF14 is a non-canonical hormone receptor for strigolactone. Nature 536(7617):469-473 doi:10.1038/nature19073

Zadnikova P, Petrasek J, Marhavy P, Raz V, Vandenbussche F, Ding ZJ, Schwarzerova K, Morita MT, Tasaka M, Hejatko J, Van Der Straeten D, Friml J, Benkova E (2010) Role of PIN-mediated auxin efflux in apical hook development of Arabidopsis thaliana. Development 137(4):607-617. doi:10.1242/dev.041277 